\title{
Proceeding
}

Supplementary Issue: Spring Conferences of Sports Science. Costa Blanca Sports Science Events, 14-15 June 2019. Alicante, Spain.

\section{Self-physical and emotional perception in volleyball for drop out}

\author{
GAETANO ALTAVILLA ${ }^{1}$, DANTE FORTE², TIZIANA D'ISANTO² \\ ${ }^{1}$ Faculty of Kinesiology, University of Split, Split, Croatia \\ 2University of Salerno, Italy
}

\begin{abstract}
Very often, during the annual planning and scheduling of the objectives of the various team sports sessions, one is overwhelmed by the fear of lack of time, and very important aspects, erroneously considered secondary, including the psychological aspect, are left out. In volleyball, in order to achieve maximum results, it is necessary to start at a young age and to commit oneself a lot, but not always enough, because it is a selective sport. The purpose of the study is to study, in different groups of athletes (6-9 years, 9-12 years, 14-18 years) of volleyball, how they deal emotionally and physically with the physical and emotional workloads and especially if you find physical and mental well-being. The method of the study is qualitative/quantitative and the administration of 10 questions: 5 to identify the physical self-perception and 5 for the emotional one, is done anonymously. The data shows that the self-perception for physical performance is on average positive and the self-perception for motivation performance is on average negative. This data is significant for the perceptive state of the athletes to whom it is necessary to refer in order to realistically face the problem. Given the data and their significance, the study must be deepened with a more significant and detailed sample of data. Keywords: Self-perception; Physical and emotional workload; Physical and mental well-being.
\end{abstract}

\section{Cite this article as:}

Altavilla, G., Forte, D., \& D'Isanto, T. (2019). Self-physical and emotional perception in volleyball for drop out. Journal of Human Sport and Exercise, 14(4proc), S1022-S1029. doi:https://doi.org/10.14198/ihse.2019.14.Proc4.64

Corresponding author. Faculty of Kinesiology, University of Split, Split, Croatia. http://orcid.org/0000-0001-8436-7819

E-mail: gaetano.altavilla@libero.it

Supplementary Issue: Spring Conferences of Sports Science. Costa Blanca Sports Science Events, 14-15 June 2019. Alicante, Spain.

JOURNAL OF HUMAN SPORT \& EXERCISE ISSN 1988-5202

(c) Faculty of Education. University of Alicante

doi:10.14198/jhse.2019.14.Proc4.64 


\section{INTRODUCTION}

Often during the annual planning and scheduling of objectives (Altavilla \& Raiola, 2018), of the various sessions of team sports (D'Elia et al, 2019), very important aspects are left out, erroneously considered secondary, including the psychological aspect (Valentini et al, 2018). In a team sport, such as volleyball, in order to achieve the best performance, it is necessary to start at a young age and work hard, but not always enough because it is a fairly selective sport. When it comes to motivation (Cirillo et al, 2016) you never know where to start. There are coaches who believe that motivation is an indefinable gift of nature, so an athlete either owns it or not. To think that athletes want or do not want to do something "by nature" or that only the coach can give them the motivation to do it is not only an illusory expectation (D'Elia et al, 2018), but it can be completely negative. Often athletes who oppose the coach's indications are strongly motivated to sport (Raiola \& Altavilla, 2015); in fact, they are only not motivated to accept the structures and methods (Pisapia et al, 2019) imposed by their coach. The phenomenon of "Drop out", i.e. the early abandonment of sport, is a big problem especially for team sports such as volleyball (Di Tore et al 2018). In fact, it is a very "technical" sport (Gaetano, R. 2012), where to be able to play while having fun you must have acquired skills (Forte et al, 2019; Viscione et al, 2019) that require time and patience (Raiola, 2017). Volleyball is a sport with technical, physical (Tiziana, D., et al 2017) and psychological characteristics (D'lsanto et al, 2017), moreover it is necessary to evaluate also the basic functional qualities (Forte et al, 2019). The performance is also linked to other qualities such as neuro-muscular coordination (Raiola, 2013,2014), motor control (Raiola, 2017), tactical attitudes and motivational characteristics (D'Isanto et al, 2018). In this sport, as in other, to test the players (Alminni et al, 2019) is indispensable for several reasons: allows us to evaluate their potentials (Alminni \& Altavilla, 2019), their athletic (Ferrara et al, 2019) and technical qualities (D'Isanto et al, 2019; Federici et al, 2019).

The purpose of the study is to investigate, in different groups of athletes (6-9 years, 9-12 years, 14-18 years) of volleyball, how they deal emotionally and physically with the physical and emotional workloads and, above all, if you find physical and mental well-being.

\section{RESEARCH METHOD}

For this research the case study was chosen because it allows to place emphasis on the detailed contextual analysis of a limited number of events or conditions and their relationships. The construction of the sample took place through a non-probabilistic sampling procedure subdividing the groups by age (6-9 years; 9-12 years; $14-18$ years).

The method of the study is qualitative/quantitative, administering through a special online platform a questionnaire of 10 questions: 5 to identify the physical self-perception and 5 for the emotional one, in total anonymity so as not to incur in false data. The study was submitted to volleyball athletes of both sexes and age groups of different. The study involved 60 athletes divided into 3 groups: 20 boys aged between 6 and 9 years, 20 boys aged between 9 and 12 years and 20 other girls aged between 14 and 18 years. Contents are established in advance, standardization in reference to the uniformity of the stimuli offered and high structuring as the respondent cannot come out of the established track. To avoid external influences in the respondents was decided to administer the questionnaire through the online platform Google drive "forms".

In order to assess the quality of the instrument, a pre-test with similar characteristics was carried out prior to administration. Attention has allowed to evaluate the effectiveness of the tool by identifying some distortions arising from the articulation of the questionnaire. The pre-test suggested important methodological indications 
to refine the specification of the most relevant concepts of the research, for their operational definition and, therefore, for the final drafting of the questionnaire: for example, some indicators were revised, eliminating those semantically redundant or invalid compared to the indicated size.

The main topic of the questionnaire is perception, we first investigated the physical and then the emotional perception. All data are expressed as average and percentage for each group. The Kendall Test Tau was used to determine the level of correlation between non-parametric variables of the three groups.

Statistical analysis was performed using SPSS 22.0 (SPSS Inc., Chicago, IL, USA).

\section{RESULTS}

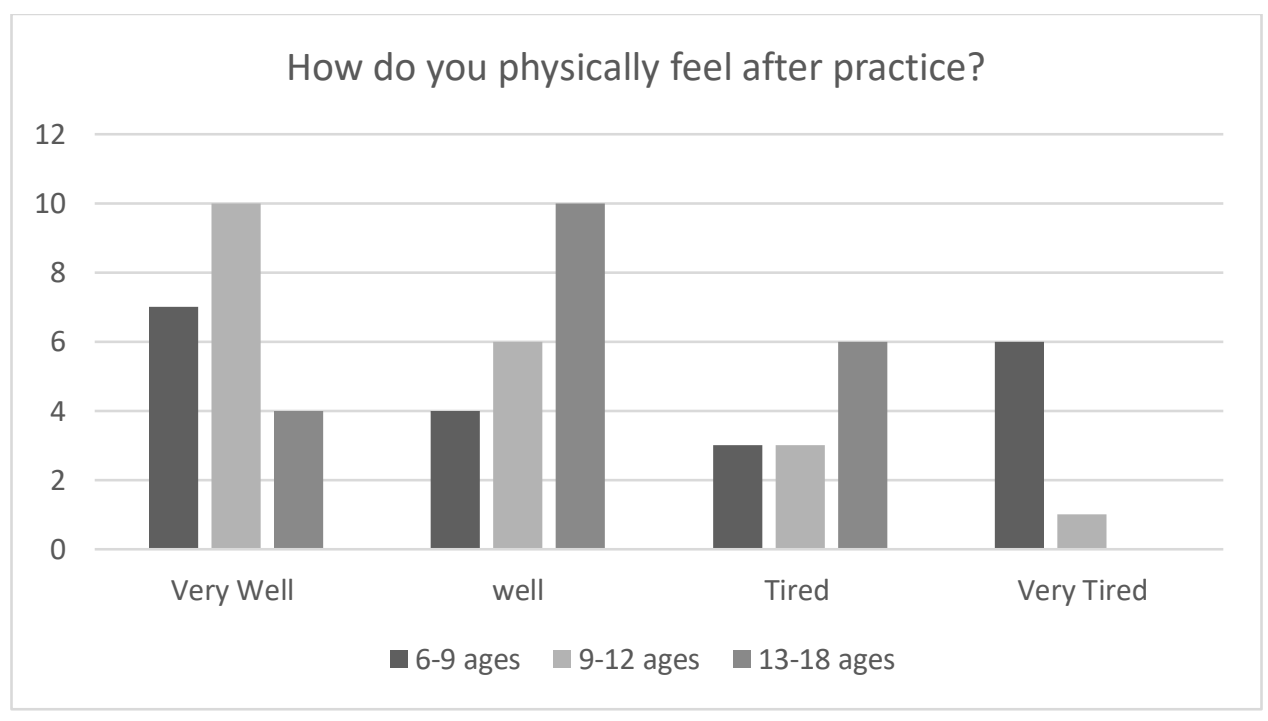

Figure 1. Physical self-perception after training.

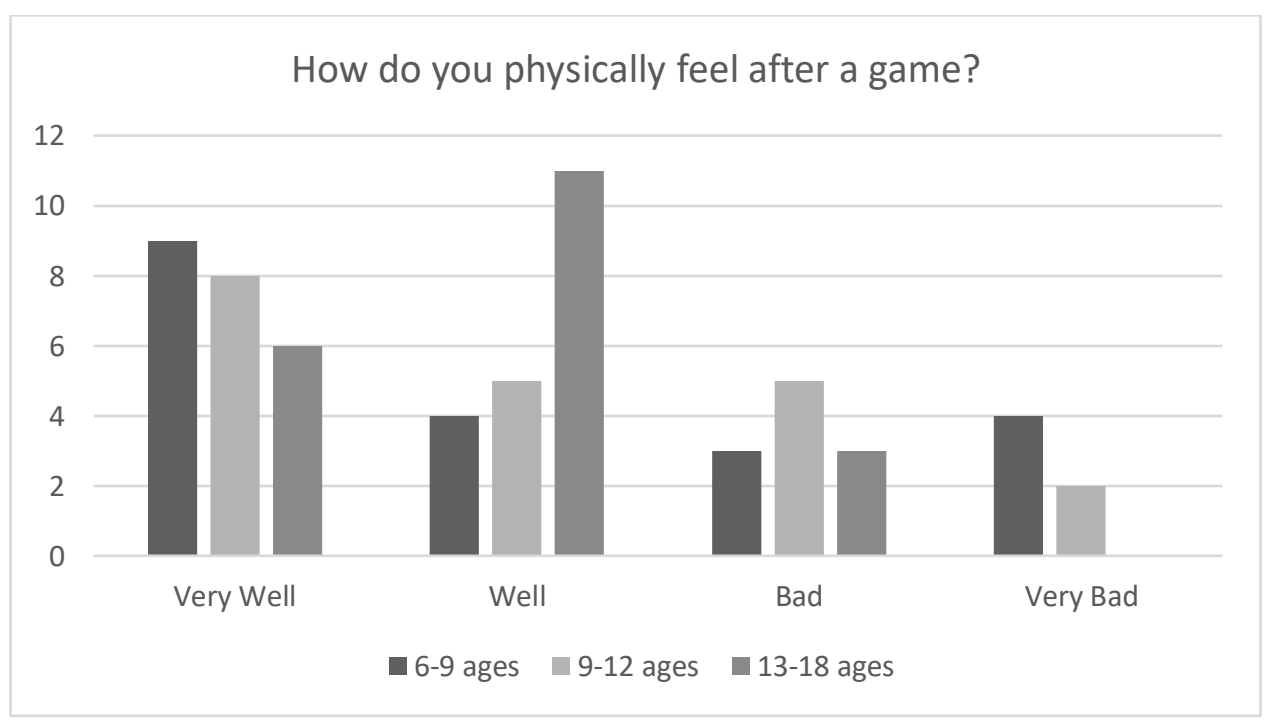

Figure 2. Physical self-perception after a race. 


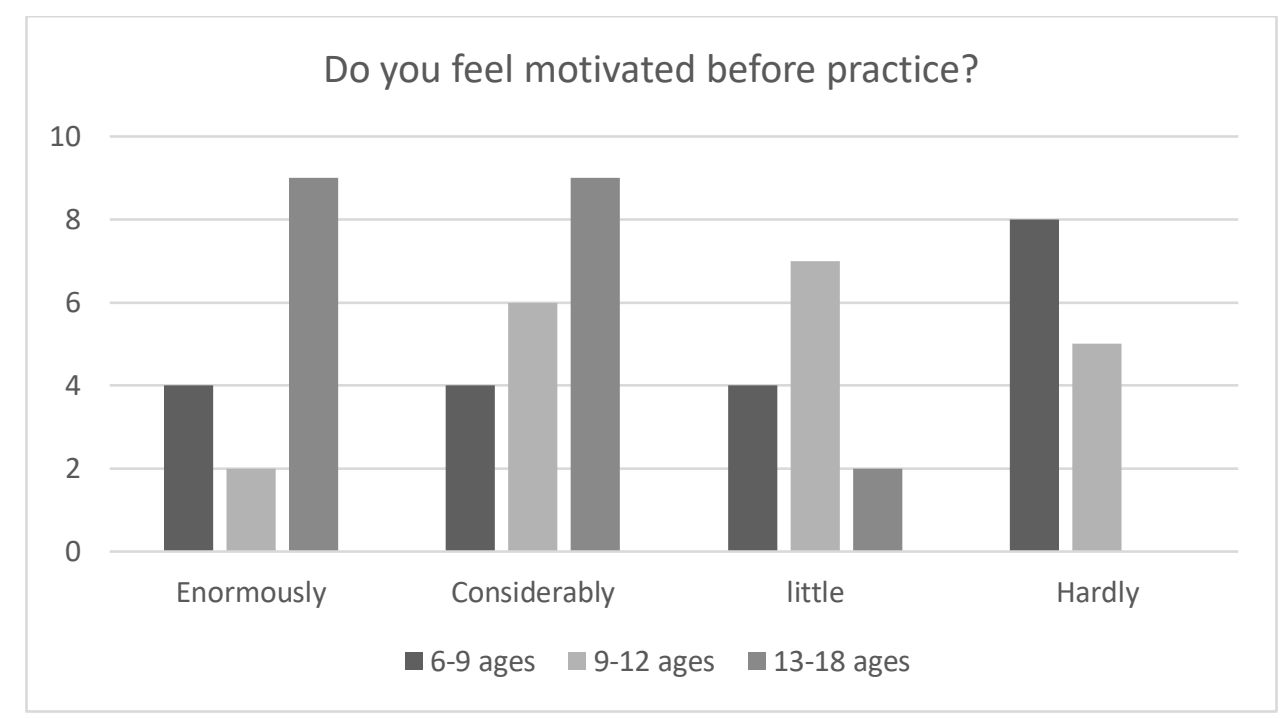

Figure 3. Emotional self-perception before training.

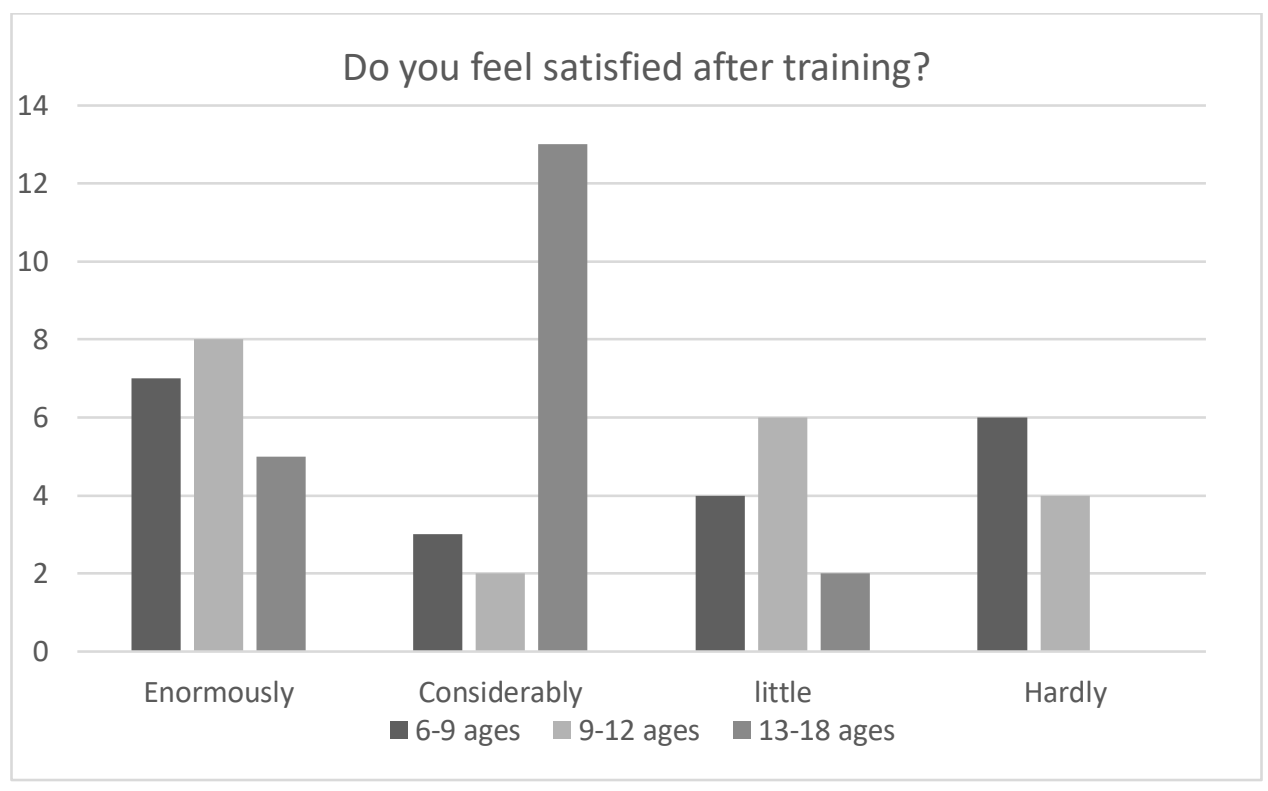

Figure 4. Emotional self-perception after training. 


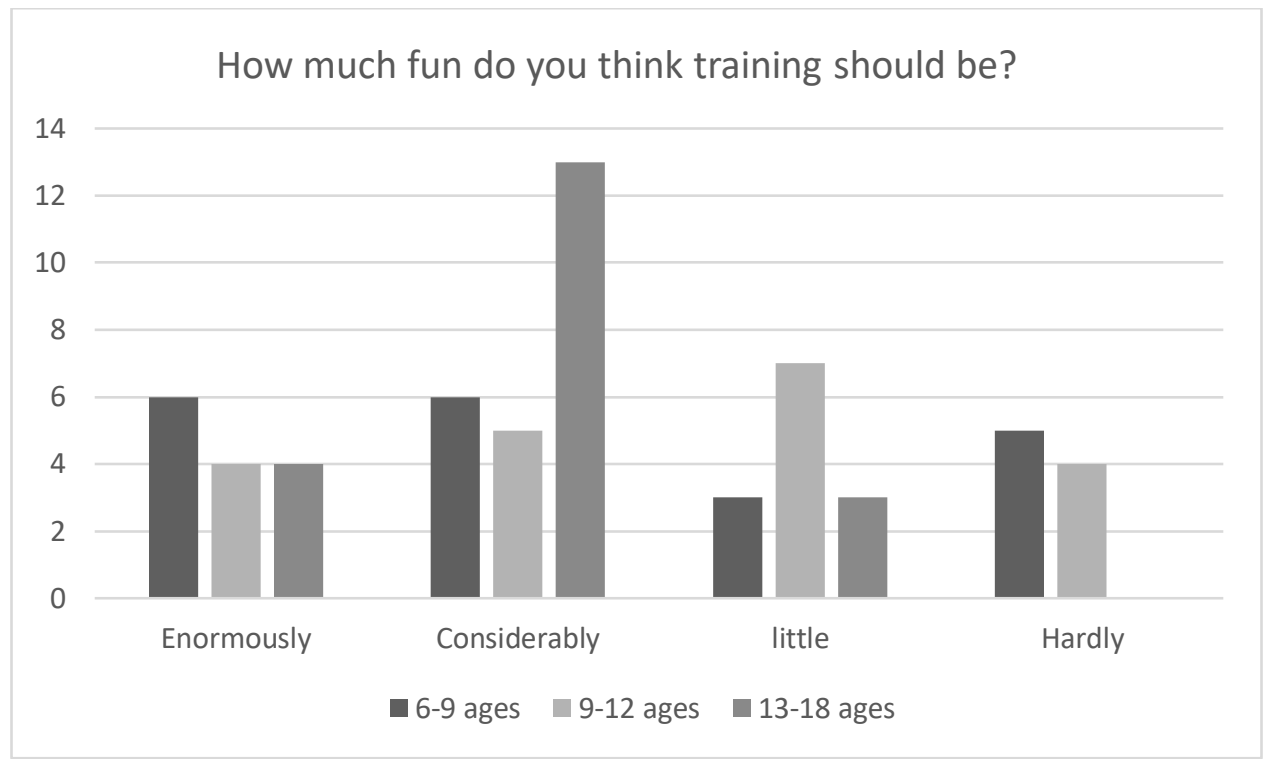

Figure 5. Importance of the playful aspect in training.

Table 1. Correlation Tau Kendall between the levels of physical and emotional perception (6-9 years)

\begin{tabular}{|lll|c|c|}
\hline & & VAR00001 & VAR00005 \\
\hline \multirow{3}{*}{ Kendall Tau Test } & \multirow{3}{*}{ Correlation coefficient } & 1.000 & .431 \\
& & Sign. (with two tails) &. & .128 \\
& \multirow{2}{*}{ VAR00001 } & N & 9 & 9 \\
\cline { 2 - 5 } & \multirow{2}{*}{ VAR0005 } & Correlation coefficient & .431 & 1.000 \\
& & $\mathrm{~N}$ & .128 &. \\
& & 9 & 9 \\
\hline
\end{tabular}

Discreet correlation between the two levels (physical and emotional) of perceived well-being, therefore the two levels are perceived similarly by the group of $6-9$ years.

Table 2. Correlation Tau Kendall between the levels of physical and emotional perception (9-12 years)

\begin{tabular}{|lll|c|c|}
\hline & & VAR00002 & VAR00006 \\
\hline \multirow{4}{*}{ Kendall Tau Test } & \multirow{3}{*}{ VAR00002 } & Correlation coefficient & 1.000 & .092 \\
& & Sign. (with two tails) &. & .744 \\
& $\mathrm{~N}$ & 9 & 9 \\
\cline { 2 - 5 } & \multirow{2}{*}{ VAR00006 } & Correlation coefficient & .092 & 1.000 \\
& & Sign. (with two tails) & .744 &. \\
& $\mathrm{~N}$ & 9 & 9 \\
\hline
\end{tabular}

Low correlation, even if negative, between the two levels (physical and emotional) of perceived well-being, therefore the two levels are perceived differently by the group of 9-12 years. 
Table 3. Correlation Tau Kendall between the levels of physical and emotional perception (13-18 years)

\begin{tabular}{|lll|c|c|}
\hline & & VAR00003 & VAR00007 \\
\hline \multirow{3}{*}{ Kendall Tau Test } & \multirow{3}{*}{ VAR00003 } & Correlation coefficient & 1.000 & .424 \\
& & Sign. (with two tails) &. & .130 \\
& $\mathrm{~N}$ & 9 & 9 \\
\cline { 2 - 5 } & \multirow{2}{*}{ VAR00007 } & Correlation coefficient & .424 & 1.000 \\
& & Sign. (with two tails) & .130 &. \\
& $\mathrm{~N}$ & 9 & 9 \\
\hline
\end{tabular}

Discreet correlation between the two levels (physical and emotional) of perceived well-being, therefore the two levels are perceived similarly by the group of 13-18 years old.

\section{DISCUSSION}

This research stems from the desire to deepen knowledge about the perception of athletes and what drives them to abandon. From the data obtained from the questionnaire administered, there is an average positive physical self-perception in all age groups analysed and it seems possible not to attribute to it the motivation to abandon this sport (Figure 1 and 2). Differently from the results on emotional self-perception, where we can see average negative results.

There is a low motivation before training (Figure 3), a possible symptom of a sporting choice not because one's own choice, especially in the age group of 6-9 years and 9-12 years, differently from the age group of $13-18$ years where the motivation is high, about $90 \%$.

To confirm what has been said so far is the clearly negative result in the first two groups analysed on the satisfaction of athletes at the end of training (Figure 4), and clearly contrary result in the 13-18 years.

Another aspect to consider, in the search for motivation to abandon, is the clearly positive result about the demand of athletes on the recreational aspect (Figure 5) that should have the workouts, and in the absence of fun in them can lead to abandonment. Finally, through the use of the Kendall Tau Test, we have tried to establish if the level of correlation and therefore of self-perception (physical and emotional), in the different ages, is similar; something that is denied by the results of the Kendall Tau Test.

\section{CONCLUSIONS}

We speak of a drop-out in sport to indicate the early, and often permanent, abandonment of sport, especially by adolescents. This is a worrying phenomenon and difficult to interpret.

The absence of the play component, the lack of fun and the onset of boredom, the psychological pressure of the performance and the winning expectations from the surrounding environment, conflicts and guilty judgments can generate a feeling of incompetence and fear of getting involved as a result of any failures, as well as experiences of anxiety and stress, preventing him from dealing with the experience in a positive way and, in fact, causing the loss of interest in the activity carried out (Burnout) and the interruption of the sport (drop-out), which is experienced as a failure and, consequently, as a source of insecurity. The premature abandonment of sport has negative effects on the growth of the athlete on a physical, psychological and social level, as it leads to an increase in sedentary lifestyles. 
Given the data and their significance, the study should be deepened with a more significant and detailed sample of data.

\section{REFERENCES}

Alminni, C., Altavilla, G., Peluso Cassese, F., Ceciliani, A., D'Isanto, T. (2019). Physical and motor tests to estimate the improvement of the float serve, Journal of Human Sport and Exercises, 14(2proc), S245-S250. https://doi.org/10.14198//hse.2019.14.proc2.13

Altavilla G., Raiola G. (2018). Periodization: finalization of the training units and of the load's entity, The European Proceedings of Social \& Behavioural Sciences EpSBS, 03.33, ISSN: 2357-1330. https://doi.org/10.15405/epsbs.2018.03.33

Cirillo, G., Nughes, E., Acanfora, A., Altavilla, G., D'Isanto, T. (2016). Physical and sport education testing by quantitative and qualitative tools in assessment in senior school: a proposal, Sport Science, 9 (S1):97-101.

D'Elia, F., D'Isanto, T., \& Altavilla, G. (2019). Training and performance in the transition period. Journal of Human Sport and Exercise, 14(2proc), S258-S262. https://doi.org/10.14198/ihse.2019.14.Proc2.15

D'Elia, F., Mazzeo, F., \& Raiola, G. (2018). The core curriculum in the university training of the teacher of physical education in Italy. Journal of Human Sport and Exercise, 13(2proc), S413-S420. https://doi.org/10.14198/ihse.2018.13.Proc2.25

D'Isanto, T., Altavilla, G., Raiola, G. (2017). Teaching method in volleyball service: Intensive and extensive tools in cognitive and ecological approach. Journal of Physical Education and Sport, 17(S5): 2222-2227.

D'isanto, T., Di Tore, P.A., Altavilla, G. (2018). Correlation of the anthropometric characteristics and the ability to jump in volleyball, Journal of Human Sport and Exercise, 13(2): 393-400. https://doi.org/10.14198/ihse.2018.13.proc2.23

D'Isanto, T., D'Elia, F., Raiola, G., Altavilla, G. (2019). Assessment of sport performance: theoretical aspects and practical indications. Sport Mont, 17(1): 79-82. https://doi.org/10.26773/smj.190214

Di Tore, A.P., Raiola, G., D'Isanto, T. (2018). Situation awareness in sports science: Beyond the cognitive paradigm, Sport Science, 11(1):44-48.

Ferrara, F., Izzo, R., Ceciliani, A., Di Tore, A.P. (2019a). Pilot study on the testing of Power Glove applied to volleyball, Journal of Human Sport and Exercise, 14 (Proc2):S233-S238. https://doi.org/10.14198//hse.2019.14.proc2.11

Forte, D., Ceciliani, A., Izzo, R., Altavilla, G. (2019). Transition period: Pilot study on performance reduction of ability to jump in volleyball, Journal of Human Sport \& Exercise, vol. 14(2):221-227. https://doi.org/10.14198/ihse.2019.14.proc2.09

Forte, D., Ceciliani, A., Izzo, R., Altavilla, G. (2019). Transition period: Pilot study on performance reduction of ability to jump in volleyball, Journal of Human Sport and Exercise, 14 (Proc2): S221S227. https://doi.org/10.14198//hse.2019.14.proc2.09

Gaetano, R. (2012). Didactics of volleyball into the educate program for coaches/trainers/technicians of Italian Federation of Volleyball (FIPAV). Journal of Physical Education and Sport, 12 (1): 25-29.

Raiola, G. (2013). Body knowledge and motor skills, Knowledge Cultures, 1(6):64-72.

Raiola, G. (2014). Teaching method in young female team of volleyball, Journal of Physical Education and Sport, 14 (1): 74-78.

Raiola, G. (2017). Motor learning and teaching method, Journal of Physical Education and Sport, 17(S5): 2239-2243. 
Raiola, G., Di Tore, P.A. (2017) Motor learning in sports science: Different theoretical frameworks for different teaching methods, Sport Science, 10, pp. 50-56.

Raiola, G., Altavilla, G. (2015). Anxiety In The Youth Physical And Sport Activity, Mediterranean Journal of Social Sciences, 6 (3): 227-230.

Tiziana, D., Antonetta, M., Gaetano, A. (2017). Health and physical activity, Sport Science, 10 (1): 100 105.

Valentini, M., Riccardi, F., Raiola, G., Federici, A. (2018). Educational research: Motor area and relational area during children's personality development, Journal of Physical Education and Sport, 18(327): 2157-2174. 